\title{
Optimization of Small Scale Wind Turbine Blades for Low Speed Conditions
}

\author{
Mohammadreza Mohammadi, Alireza Mohammadi, Moona Mohammadi, and Hamid Neisi Minaei
}

\begin{abstract}
This paper proposes a new optimization method for blades of 4 small scale wind turbines including $5 \mathrm{KW}, 10 \mathrm{KW}$, $15 \mathrm{KW}$ and $20 \mathrm{KW}$ wind turbines while objective function is maximum output torque. This optimization process is performed assuming a constant wind speed of $7 \mathrm{~m} / \mathrm{s}$ which is classified as low speed condition. In this research based on a primary design, the blade is divided into three sections and best airfoils with optimum attack angles are determined while chord distribution, relative wind angle distribution, blade length and number of blades are considered constant. Results show that using this new optimization method can increase the output torque up to 19.5 percent.
\end{abstract}

Index Terms - Genetic algorithm, optimization, turbine blade, wind turbine.

\section{INTRODUCTION}

Nowadays Wind turbine industry is becoming one of the best choices for energy production among all renewable energy choices. In recent years this industry have been much more interesting than hydropower industry which has a huge environmental effects. In financial aspect, wind industry shows a very dramatic progress which is expected to compete with fossil fuel energy generation in following years [1].

Regarding the importance of turbine blade in its energy generation lots of researches have been developed to make the blade more efficient. Nicolette Arnalda Cencelli optimized a designed blade. In this research some airfoils were designed by Xfoil software for different sections. Results showed new airfoils can increase the output power [2].

Liu et al. and Xudong et al. worked on rotor blade chord and twist distributions. BEM analysis and CFD methods were used to determine the effect of design changes [3], [4].

Ozge Polat and Ismail $\mathrm{H}$. Tuncer worked on aerodynamic shape optimization based on Genetic Algorithm and Blade Element Momentum theory. Optimization studies were

Manuscript received September 30, 2014; revised April 27, 2015. This work was supported in part by the Bushehr Gas Company and Khuzestan Water \& Power Authority. Authors take this opportunity to express a deep sense of gratitude to Standard and Research Office of Dam- Hydro Power Division of KWPA cordial support, valuable information and guidance, which helped us in completing this task through various stages.

Mohammadreza Mohammadi was with University of Sistan and Baluchestan, Zahedan, 9816745639 Iran. He is now with the Bushehr Gas Company, National Iranian Gas Company, (NIGC) 75157-53174 Iran (tel.: +989166047873; e-mail: mhrz_mohammadi@yahoo.com.au).

Alireza Mohammadi is with the Turbine Machine M.E. Company, Ahvaz, Iran (e-mail: aalirezamohammadi@gmail.com).

Moona Mohammadi is with Khuzestan Water \& Power Authority, Ahvaz, Iran (e-mail: moona_mohammadi@yahoo.com).

Hamid Neisi Minaei is with Azad University of Shoushtar, Shoushtar, Iran (e-mail:minaeihamid@yahoo.com). performed to maximize power production of specific wind speed, rotor speed, and rotor diameter. In this research, XFOIL was used to provide sectional aerodynamic loads [5].

Pourrajabian et al. worked on the influence of the air density variation with altitude on the performance of a small horizontal axis wind turbine blade [6].

Sharifi and Nobari optimized pitch angle, along wind turbine blade, based on an aerodynamic code. This aerodynamic code could accurately predict the aerodynamics of horizontal axis wind turbines [7].

\section{BLADE DESIGN THEORIES}

Some theories have been developed for horizontal axis wind turbine blade design and performance prediction known as Blade Element theory, Momentum theory and Blade Element Momentum (BEM) theory.

Blade Element Momentum theory combines Momentum theory and Blade Element theory to calculate the blade shape and to predict the performance parameters of the rotor for ideal and steady operating conditions.

In Blade Element Momentum theory $\lambda_{r}$ is defined as local tip speed ratio and calculated as equation 1 :

$$
\lambda_{r}=\frac{r \Omega}{U}
$$

where $r$ is local blade radius, $\Omega$ is blade angular velocity and $U$ is stream velocity. Tip velocity ratio $(\lambda)$ is defined as tip velocity to stream velocity ratio (equation 2 ). Tip velocity ratio is selected based on turbine performance condition and for $\lambda=10$ and three bladed turbine, the best performance will be obtained [8], [9]. According to equation 3 angle of relative wind angle with rotation plane can be obtained.

$$
\begin{gathered}
\left(\lambda_{r}\right)_{i}=\lambda \frac{r_{i}}{R} \\
\phi_{i}=\frac{2}{3} \tan ^{-1}\left(\frac{1}{\left(\lambda_{r}\right)_{i}}\right)
\end{gathered}
$$

Chord distribution in each section of the blade can be obtained from equation 4:

$$
C_{i}=\frac{8 \pi r_{i}}{B C_{L \text { design }}}\left(1-\cos \left(\phi_{i}\right)\right)
$$

Pitch angle of blade chord in each section can be obtained from equation 5: 


$$
\left(\theta_{p}\right)_{i}=\phi_{i}-\left(\alpha_{\text {design }}\right)_{i}
$$

Finally axial induction factor and Angular induction factor can be obtained from equations 6 and 7 .

$$
\begin{gathered}
a=\frac{1}{1+\frac{4 \sin ^{2}(\phi)}{\sigma_{\text {design }}^{\prime} C_{L \text { design }} \cos (\phi)}} \\
a^{\prime}=\frac{1-3 a}{4 a-1}
\end{gathered}
$$

where

$$
\left(\sigma^{\prime}\right)_{\mathrm{design}}=\frac{B c_{i}}{2 \pi r}
$$

In equations 1 to $8 i$ is number of each blade section. These equations suggest primary design of the blade while tip loss effect is not considered so for final design, equations 9 to 15 should be passed.

$$
\phi_{i}=\tan ^{-1}\left(\frac{U(1-a)}{\Omega r\left(1+a^{\prime}\right)}\right)=\tan ^{-1}\left(\frac{(1-a)}{\lambda_{r}\left(1+a^{\prime}\right)}\right)
$$

Regarding obtained $\phi_{i}$ from equation 9 attack angle is recalculated.

$$
\alpha_{i}=\phi_{i}-\left(\theta_{p}\right)_{i}
$$

In equation 10 the value of $\left(\theta_{p}\right)_{i}$ is obtained from equation 5.

Tip loss effect can be calculated from equation 11 and would be applied in equations 13, 14 and 15 .

$$
F=\frac{2}{\pi} \cos ^{-1}\left(\exp \left(-\frac{\frac{B}{2}\left(1-\frac{r}{R}\right)}{\frac{r}{R} \sin (\phi)}\right)\right)
$$

Thrust force coefficient can be obtained from equation 12 .

$$
C_{T}=\frac{\sigma^{\prime}(1-a)^{2}\left(C_{L} \cos (\phi)+C_{d} \sin (\phi)\right)}{\sin ^{2}(\phi)}
$$

In equation 12 if $C_{T}<0.96$ then:

$$
a=\frac{1}{1+\frac{4 F \sin ^{2}(\phi)}{\sigma_{i}^{\prime} C_{L} \cos (\phi)}}
$$

And if $C_{T}>0.96$ :

$$
a=\frac{1}{F}\left[0.143+\sqrt{.0203-0.6427\left(0.889-C_{T}\right)}\right]
$$

New Angular induction factor will be obtained from equation 15 .

$$
a^{\prime}=\frac{1}{\frac{4 F \cos \phi}{\sigma_{i}^{\prime} C_{L}}-1}
$$

In equation 12 to $15 \sigma_{i}^{\prime}$ can be obtained from equation 16 .

$$
\sigma_{i}^{\prime}=\frac{B c_{i}}{2 \pi r}
$$

New axial and angular induction factors will be used to recalculation of parameters and this loop will continue until the difference of two frequent values of axial induction factors and difference of two frequent values of angular induction factors become less than a certain amount and reaches to a certain accuracy.

\section{PRIMARY DESIGN}

Rotor radius for each turbine blade can be calculated by equation 17.

$$
P=\frac{1}{2} \rho \pi R^{2} U^{3} C_{p} \eta_{m} \eta_{g}
$$

where $P_{e}$ is output power, $R$ is rotor diameter (m), $\rho$ is air density $\left(1.225 \mathrm{~kg} / \mathrm{m}^{2}\right), U$ is relative wind velocity $(7 \mathrm{~m} / \mathrm{s}), C_{p}$ is power coefficient (0.47), $\eta_{m}$ is mechanical efficiency (0.9) and $\eta_{g}$ is Transition coefficient (0.9).

According to equation (17), $5 \mathrm{KW}, 10 \mathrm{KW}, 15 \mathrm{KW}$ and $20 \mathrm{KW}$ turbine blade would have $4.5 \mathrm{~m}, 6.5 \mathrm{~m}, 8 \mathrm{~m}$ and $9 \mathrm{~m}$ blade radius for this wind condition respectively. This wind speed $(7 \mathrm{~m} / \mathrm{s})$ is average speed of many windy sites in low speed countries such as South Africa and Iran.

Different airfoils have been designed for wind turbines while each one has its own special aerodynamic properties and generated power. NACA 63-215 series airfoil have been used in many modern horizontal axis wind turbines [10] so primary design was performed assuming this airfoil for all the blade span. Fig. 1 shows One meter profiles NACA 63-215 [11].

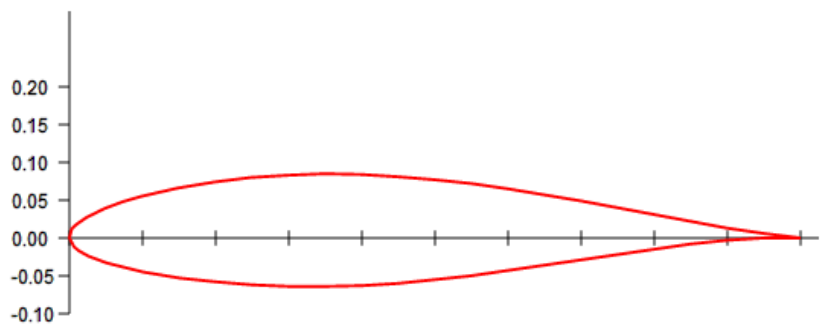

Fig. 1. One meter profiles NACA 63-215 [11]. 


\section{IMPLEMENTATION OF OPTIMIZATION}

Analytical optimization process was used to find optimum airfoils and attack angles using a written code in MATLAB. In this code Blade Element Momentum analysis was used to select best airfoils with optimum attack angles.

In this research, airfoil type and attack angle are optimization variables while chord distribution, relative wind angle distribution, blade length and number of blades considered as constants. Table I shows optimization problem briefly.

Three sections of blade were considered: root, mid and tip. Root of the blade is considered at $20 \%$ of the blade. Selected section for optimization is middle of the root. The second part of the blade is mid which is between root and tip; selected section in this part is middle of the blade $(50 \%$ of blade radius). The third part is tip which is $5 \%$ of blade end.

TABLE I: OPTIMIZATION PROBLEM DEFINITION

\begin{tabular}{|c|c|}
\hline Objctive Function & Output torque \\
\hline Variables & Attack Angle, Airfoil type \\
\hline Attack angle range & 0 -12 degrees \\
\hline Constants & $\begin{array}{c}\text { Turbine Diameter, Number of } \\
\text { blades,chord length, relative wind angle }\end{array}$ \\
\hline
\end{tabular}

Airfoils are selected from Table II. These airfoils were designed and used for wind turbine blades [12]-[16].

TABLE II: AIRFOIL DATA BASE

\begin{tabular}{|l|l|l|l|}
\hline 1 & NACA 63-215 & 24 & FX 61-168 \\
\hline 2 & NACA 63-218 & 25 & FX 61-184 \\
\hline 3 & NACA 63-221 & 26 & FX 38-153 \\
\hline 4 & NACA 63-415 & 27 & FX 66-S-161 \\
\hline 5 & NACA 63-418 & 28 & FX 66-S-196 \\
\hline 6 & NACA 63-421 & 29 & FX 66-S-196 V1 \\
\hline 7 & NACA 64-415 & 30 & FX 66-17A-17 \\
\hline 8 & NACA 64-421 & 31 & FX 66-17AII-182 \\
\hline 9 & NACA 65-415 & 32 & NACA 4415 \\
\hline 10 & NACA 65-421 & 33 & NACA 4412 \\
\hline 11 & FX S 02/1-158 & 34 & S814 \\
\hline 12 & FX S 03-182 & 35 & S809 \\
\hline 13 & FX S 02-196 & 36 & E387 \\
\hline 14 & FX 60-126/1 & 37 & SD2030 \\
\hline 15 & FX 60-157 & 38 & S822 \\
\hline 16 & FX 60-177 & 39 & S834 \\
\hline 17 & FX 63-137 & 40 & SG6043 \\
\hline 18 & FX 63-143 & 41 & SG6040 \\
\hline 19 & FX 63-145 & 42 & SG6041 \\
\hline 20 & FX 63-147 & 43 & SG6042 \\
\hline 21 & FX 63-158 & & \\
\hline 22 & FX 61-147 & & \\
\hline 23 & FX 61-163 & & \\
\hline & & & \\
\hline
\end{tabular}

\section{RESULTS}

TABLE III: RESULTS OF FOUR WIND TURBINE BLADES OPTIMIZATION

\begin{tabular}{|c|c|c|c|}
\hline & First section & Second section & Third section \\
\hline $\begin{array}{l}\text { Section radius for } \\
4.5 \mathrm{~m} \text { blade }\end{array}$ & 0.45 & 2.25 & 4.38 \\
\hline $\begin{array}{l}\text { Section radius for } \\
6.5 \mathrm{~m} \text { blade }\end{array}$ & 0.65 & 3.25 & 6.33 \\
\hline $\begin{array}{l}\text { Section radius for } \\
8 \mathrm{~m} \text { blade }\end{array}$ & 0.8 & 4 & 7.8 \\
\hline $\begin{array}{l}\text { Section radius for } \\
9 \mathrm{~m} \text { blade }\end{array}$ & 0.9 & 4.5 & 8.77 \\
\hline Optimized airfoil & $\begin{array}{l}\text { FX } \\
66-S-196 \text { v1 }\end{array}$ & $\begin{array}{ll}\text { FX } & 66-S-196 \\
\text { v1 } & \\
\end{array}$ & $\begin{array}{l}\text { FX 66-S-196 } \\
\text { v1 }\end{array}$ \\
\hline $\begin{array}{l}\text { Optimized attack } \\
\text { angle (degree) }\end{array}$ & 8 & 8 & 8 \\
\hline
\end{tabular}

Optimization results show for three sections all considered small scale turbine blades, for all three sections, FX 66-S-196 v1 was selected while attack angle was 8 degree (shown in Table III).

Total amount of torque increase is shown in Table IV.

TABLE IV: COMPARISON OF OPTIMIZED BLADE WITH THE PRIMARY DESIGN

\begin{tabular}{|l|l|l|l|}
\hline & $\begin{array}{l}\text { Output torque in } \\
\text { Primary design }\end{array}$ & $\begin{array}{l}\text { Output torque in } \\
\text { optimized blade }\end{array}$ & $\begin{array}{l}\text { Increase } \\
\text { percentage }\end{array}$ \\
\hline 4.5 m blade & 414.34 & 446.45 & 7.7 \\
\hline $6.5 \mathrm{~m}$ blade & 1262.7 & 1448.1 & 14.6 \\
\hline $8 \mathrm{~m}$ blade & 2373.4 & 2800 & 17.9 \\
\hline $9 \mathrm{~m}$ blade & 3397.5 & 4059.7 & 19.5 \\
\hline
\end{tabular}

\section{CONCLUSION}

In this paper four small scale wind turbines were optimized. Design and optimization was performed for conditions where average wind velocity is lower than International wind energy market. This different condition causes different design parameters distribution in same output power. Reynolds number across the blade will be different too. Regarding many windy sites in considered low speed countries like Iran, South Africa etc. have average wind speed of $7 \mathrm{~m} / \mathrm{s}$, this research is based on this velocity.

In this paper three sections in root, mid and tip of the blade were considered. The reason of different section selection was different conditions in root, mid and tip of the blade like Reynolds number, relative wind angle, axial induction factor etc. Considering airfoils designed for wind turbines, the best airfoils with the best attack angles were selected for each section.

This research showed despite three sections were selected across the blade, just one airfoil and one attack angle were selected for all sections. Comparing blades of different turbines shows this results is deduced in all of them.

Although this result may not be satisfying at the first time, comparing these information with results of optimization of medium scale wind turbine blades [17], [18] with exactly same sectioning method where three different airfoils were selected across the blade shows in small scale blades and in assumed wind condition, blades are not long enough to have various condition across the blade. In other words primary condition such as Reynolds number and axial induction factor do not cause of different airfoil selection while in previous studies of medium scale turbines [17], [18] regarding considered blade radiuses were up to $20 \mathrm{~m}$ different airfoils were selected for each section.

These results also show FX 66-S-196 v1 is a very suitable airfoil for small scale blades for low speed condition for all root, mid and tip of the blade.

\section{REFERENCES}

[1] M. Mohammadi, A. Mohammadi, and M. Mohammadi, "Potantial of Jet stream in Iran and capacity of its energy generation," in Proc. the $22^{\text {nd }}$ Annual International Conference on Mechanical Engineering, Ahvaz, Iran, April 22-24, 2014.

[2] N. A. Cencelli, "Aerodynamic optimization of a small-scale wind turbine blade for low wind speed conditions," MS Thesis, December 2006.

[3] X. Liu, Y. Chen, and Z. Ye, "Optimization model for rotor blades of horizontal axis wind turbines," Frontiers of Mechanical Engineering in China, vol. 2, no. 4, pp. 483-488, 2007. 
[4] W. Xudong, W. Z. Shen, W. J. Zhu, J. N. Sørensen, and C. Jin, "Shape optimization of wind turbine blades," Wind Energy, vol. 12, pp. 781$803,2009$.

[5] O. Polat and I. H. Tuncer, "Aerodynamic shape optimization of wind turbine blades using a parallel genetic algorithm," in Proc. 25th International Conference on Parallel Computational Fluid Dynamics, 2013.

[6] A. Pourrajabian, M. Mirzaei, R. Ebrahimi, and D. Wood, "Effect of air density on the performance of a small wind turbine blade A case study in Iran," Journal of Wind Engineering and Industrial Aerodynamics, vol. 126, March 2014.

[7] A. Sharifi and M. R. H. Nobari, "Prediction of optimum section pitch angle distribution along wind turbine blades," Energy Conversion and Management, vol. 67, March 2013.

[8] E. Kulunk. (2011). Aerodynamics of Wind Turbines, Fundamental and Advanced Topics in Wind Power. [Online]. Available: http://www.intechopen.com/books/fundamental-and-advanced-topicsin-wind-power/aerodynamics-of-wind-turbines

[9] J. F. Manwell and J. G. McGowan, Theory Design and Application, 2nd Ed. John Wiley and Sons, 2009, ch. 3, pp. 115-134.

[10] M. M. Soa, "Issues and Prospects for the GMS," in Proc. GMSARN International Conference on Sustainable Development, Nov. 12-14, 2008.

[11] Airfoil Tools. (September 2014). [Online]. Available: http://airfoiltools.com

[12] F. Bertagnolio, N. Srensen, J. Johansen, and P. Fuglsang, Wind Turbine Airfoil Catalogue, Riso National Laboratory, Roskilde, Denmark, August 2001.

[13] S. Selig Bryan and D. M. Granahan, "Wind tunnel aerodynamic tests of six airfoils for use on small wind turbines," Department of Aerospace Engineering, University of Illinois at Urbana, November 2004.

[14] Paul G. Migliore, Wind Turbine Aeroacoustic Issues, National Renewable Energy Laboratory, California Wind Energy Consortium Forum, University of California, December 17-18, 2002.

[15] P. Giguere and M. S. Selig, "New airfoils for small horizontal axis wind turbines," Department of Aeronautical Engineering, University of Illinois at Urbana-Champaign, 1998.

[16] D. M. Somers and M. D. Maughmer, Theoretical Aerodynamic Analyses of Six Airfoils for Use on Small Wind Turbines, Port Matilda, Pennsylvania, 2002.

[17] M. Mohammadi and S. Farahat, "Optimization of $100 \mathrm{KW}$ wind turbine blade using genetic algorithm," in Proc. the $10^{\text {th }}$ International Energy Conference, Tehran, Iran, 2014.

[18] M. Mohammadi and S. Farahat, "Optimization of $60 \mathrm{KW}$ wind turbine blade using genetic algorithm," in Proc. $3^{\text {rd }}$ International Conference on Emerging Trends in Energy Conservation-ETEC, Tehran, Iran, 2014.

Mohammadreza Mohammadi was born in 1987 in Ahvaz, Iran. He got his bachelor degree of mechanical engineering from IAU Ahvaz, Iran, in 2005 and received his master degree of mechanical engineering from University of Sistan and Baluchestan , Iran, in Febraury 2014.

Since Dec. 2013, he has been with the Iranian National Company as a manager of operation and maitainance, Bushehr, Iran. He previously worked in the Optimization Laboratory of Mechanical Enginnering in University of Sistan and Baluchestan as a reaserch assistant about one year and about 3 months technical experience in the Zargan Power Plant, Iran as a summer apprentice. Mohammadi has pulished 15 papers in journals and conferences.
Some of his recent publications are: 1). Optimization of $60 \mathrm{KW}$ wind turbine blade using genetic algorithm, published in the $3^{\text {rd }}$ International Conference on Emerging Trends in Energy Conservation-ETEC 2014, Tehran, Iran. 2). Optimizing hydro power turbines in order to secure the passage of fishes in Khuzestan province, published in the Journal of Applied and Computational Mechanics, 2014. 3). Potential of jet stream in Iran and capacity of its energy generation, published in the $22^{\text {nd }}$ Annual International Conference on Mechanical Engineering, Shahid Chamran University of Ahvaz, Mechanical Engineering, April 2014, Ahvaz, Iran.

Mr. Mohammadi had been selected among tens of thousands participants in National Iranian Gas Company entrance examination in 2013. He also won the best paper award for his paper in Emerging Trends in Energy Conservation-ETEC $3^{\text {rd }}$ International conference 2014 Tehran, Iran.

Alireza Mohammadi was born in 1983 in Ahvaz, Iran. He got his bachelor and master degrees of mechanical engineering from IAU Ahvaz in 2007 and 2011 respectively.

$\mathrm{He}$ is the manager of mechanical engineering section of Turbine Machine M.E. Company, Ahvaz, Iran. He was previously a lecturer in Payame Nour University of Shoushtar and Abadan. Mohammadi has 11 publications in conferences and journals. Some of his publications are: 1). Optimizing hydro power turbines in order to secure the passage of fishes in Khuzestan province, published in the Journal of Applied and Computational Mechanics, 2014. 2). Tension analysis of $25 \mathrm{KW}$ wind turbine blade, published in the First International Conference on Emerging Trends in Energy Conservation, 2012, Tehran, Iran. 3). Potential of jet stream in Iran and capacity of its energy generation, published in the $22^{\text {nd }}$ Annual International Conference on Mechanical Engineering, Shahid Chamran University of Ahvaz, April 2014, Ahvaz, Iran.

Moona Mohammadi was born in 1976 in Abadan, Iran. She got her bachelor degree of mechanical engineering from the Tehran University of Science and Technology and her master degree of mechanical engineering from Shiraz University.

She has been with the Kouzestan Water \& Power Authority (KWPA) as an expert of hydro power turbine, Ahvaz, Iran since 2005. In recent years, she has 12 publications in conferces and journals and her research activitie is governer of hydro power turbines. Some of her published papers are: 1). Analysis of cooling air jacket and air distributor in a co-current spray dryer, published in Iranian Journal of Science and Technology, 2009. 2). Simulation of spray dryer with cooling air jacket and air disperser by computational fluid dynamics, published in 13th International Heat Transfer Conference, Sydney, Australia, 2006. 3). Optimizing hydro power turbines in order to secure the passage of fishes in Khuzestan province, published in the Journal of Applied and Computational Mechanics, 2014.

Hamid Neisi Minei was born in 1968 in Abadan Iran. He got his bachelor degree of civil engineering from Shahid Chamran University of Ahvaz, Iran and his master degree of civil engineering form Azad University of Shoushtar, Iran.

He was the manager of hydraulic section of dam construction in Dezab Consultant Company from 1991-1995. He joined Zigurat Jonub Company as a senior consultant from 1995-2000. Since 2000, he has worked as a consultant of dam construction and river engineering in Ahvaz city, Iran. 